\title{
Effect of the Bi content on the mechanical properties of a
}

\author{
Sn-Zn-Al-Bi solder alloy \\ D. Soares, C. Vilarinho, J. Barbosa, R. Silva*, M. Pinho and F. Castro \\ University of Minho, Azurém, 4800-058 Guimarães, Portugal, dsoares@dem.uminho.pt,
}

Tel: 253510220, Fax: 253516007

*TecMinho - Associação Universidade Empresa para o Desenvolvimento, 4800-058 Guimarães, Portugal

Keywords: Lead-free solder, mechanical properties, fracture, microstructure

\begin{abstract}
Because of environmental and health concerns, some alternative solder alloys, named lead-free ones, are being developed. Among them, the Sn-Zn-Al system has been studied and reveals promising properties. Selection of the solder alloys, for the electronic industry applications, is conditioned by their mechanical properties due to the stress produced in service.

The studied alloys were produced by melting the pure elements in a resistance furnace, under inert atmosphere, and pouring in a steel mould. The samples were heat treated for homogenization of the microstructure. The produced alloys were analyzed by XRF spectrometry and Scanning Electronic Microscopy (SEM/EDS) for chemical and microstructural characterization. In this work the presence of bismuth, in the range of $0-7$ weight $\%$, was evaluated in what concerns to the as-cast and homogenized microstructures and mechanical properties.

The mechanical properties of the produced alloys, in the as-cast and homogenized conditions, have been determined by tensile strength and hardness tests. The results obtained showed that bismuth has an important effect on the mechanical behavior of the alloys, namely, in the transition from ductile to brittle behavior. This behavior was correlated with the samples microstructures.
\end{abstract}

\section{Introduction}

New lead-free alloys for solders application in the electronic industry are being developed to substitute the traditional $\mathrm{Sn}-\mathrm{Pb}$ base alloys. Because of lead toxicity, health, environmental and legislation reasons (Directive 2002/96/EC) efforts have been done to substitute the traditional alloys $[1,2,3,4]$.

The $\mathrm{Sn}-\mathrm{Zn}$ based alloys, with chemical compositions close to the eutectic point, are potential candidates to substitute the traditional alloys [3,4]. This alloy system has several interesting properties for solder applications, namely, the low melting point, similar to the $\mathrm{Sn}-\mathrm{Pb}$ alloys, and good mechanical properties [2,5]. These alloys are also less expensive than the Sn-Ag-Cu alternative alloys.

The reliability of a solder joint is affected by the solder substrate interaction and by the solder mechanical properties [5,6]. The microstructure type and phase chemical composition are important factors to anticipate the solder mechanical behavior in service. 


\section{Experimental procedure}

The samples used in this work were melted from pure elements $(99.9 \mathrm{wt} . \%)$ in a resistance furnace under inert atmosphere (obtained by a constant flow of argon) and casted in a steel mold pre-heated up to $100{ }^{\circ} \mathrm{C}$. Two standard alloys were prepared for the sake of comparison with properties obtained in the studied systems. The first alloy, a $\mathrm{Sn}-\mathrm{Pb}$ based alloy, has a composition close to the actually used solder alloys in electronic soldering. The second alloy, of the Sn-Ag-Cu system, is an alternative alloy to the traditional solder alloys and to the compositions studied in this work. The alloys chemical composition was determined by XRF spectroscopy.

After melting and pouring, each alloy was heat treated using the following cycle: heating up to 120 ${ }^{\circ} \mathrm{C}$ at $10{ }^{\circ} \mathrm{C} / \mathrm{min}$, stage of $30 \mathrm{~min}$ and cooling to room temperature at $10{ }^{\circ} \mathrm{C} / \mathrm{min}$. The samples microstructures, in as-cast and after homogenization heat treatment conditions, were characterized by optical and scanning electronic microscopy and the chemical composition of the phases was determined by electronic dispersive spectroscopy (SEM/EDS). The mechanical properties of the produced alloys, in the as-cast and homogenized conditions, were determined by tensile strength tests (EN 10 002-1 1990) and hardness measurements (Vickers hardness).

\section{Results and discussion}

Chemical compositions of the produced alloys, with different Bi contents, are presented in table 1 . The alloys were prepared to have an almost constant level of $\mathrm{Zn}$ and $\mathrm{Al}$ with increasing Bi contents. Alloys 3 and 4, with similar Bi content, have a slightly different concentration of $\mathrm{Zn}$ and $\mathrm{Al}$. The standard alloys chemical composition, alloys $\mathrm{N}^{\circ} 7$ and 8 in table 1, are, respectively, the traditional $\mathrm{Sn}-\mathrm{Pb}$ alloy and the alternative $\mathrm{Sn}-\mathrm{Ag}-\mathrm{Cu}$ based lead-free alloy.

Table 1 - Chemical composition (wt. \%) of the alloys used in this work, obtained by XRF analysis.

\begin{tabular}{cccccccc}
\hline Alloy $\mathrm{N}^{\mathbf{0}}$ & $\% \mathrm{Zn}$ & $\% \mathrm{Al}$ & $\% \mathrm{Bi}$ & $\% \mathrm{~Pb}$ & $\% \mathrm{Ag}$ & $\% \mathrm{Cu}$ & $\% \mathrm{Sn}$ \\
\hline $\mathbf{1}$ & 6.9 & 0.4 & - & - & - & - & rest \\
$\mathbf{2}$ & 8.0 & 0.2 & 0.9 & - & - & - & rest \\
$\mathbf{3}$ & 5.5 & 0.5 & 2.7 & - & - & - & rest \\
$\mathbf{4}$ & 9.8 & 0.1 & 3.3 & - & - & - & rest \\
$\mathbf{5}$ & 8.0 & 0.7 & 5.4 & - & - & - & rest \\
$\mathbf{6}$ & 8.2 & 0.4 & 6.9 & - & - & - & rest \\
$\mathbf{7}$ & - & - & 2.5 & 34.2 & - & - & rest \\
$\mathbf{8}$ & - & - & - & - & 5.1 & 0.8 & rest \\
\hline
\end{tabular}

The mechanical properties were determined by tensile tests and hardness measurements in, at least, two samples of each alloy. The obtained results are presented in table 2 . The effect of bismuth content on hardness $(\mathrm{HV})$, yield and ultimate tensile strength $\left(\mathrm{R}_{0.5}\right.$ and $\left.\mathrm{R}_{\mathrm{m}}\right)$ and elongation at rupture (A) of the tested alloys is presented in fig. 1. Results are compared with the obtained values in the used standard alloys.

Table 2 - Mechanical properties obtained in the alloys, in the as-cast and homogenized conditions.

\begin{tabular}{cccccc}
\hline $\begin{array}{c}\text { Alloy } \\
\mathrm{N}^{\mathbf{0}}\end{array}$ & \multicolumn{2}{c}{$\mathrm{HV}$} & $\begin{array}{c}\mathrm{R}_{0.5 \%} \\
{[\mathrm{Mpa}]}\end{array}$ & $\begin{array}{c}\mathrm{R}_{\mathrm{m}} \\
{[(\mathrm{Mpa}]}\end{array}$ & $\begin{array}{c}\mathrm{A} \\
{[\%]}\end{array}$ \\
\hline $\mathbf{1}$ & 23 & 21 & 48 & 63 & 32.5 \\
$\mathbf{2}$ & 24 & 24 & 52 & 69 & 8.5 \\
$\mathbf{3}$ & 30 & 22 & 58 & 77 & 21.3 \\
$\mathbf{4}$ & 29 & 25 & 53 & 82 & 12,5 \\
$\mathbf{5}$ & 33 & 30 & 80 & 100 & 7.5 \\
$\mathbf{6}$ & 36 & 34 & 78 & 89 & 1.3 \\
$\mathbf{7}$ & 19 & 20 & 44 & 57 & 12.5 \\
$\mathbf{8}$ & 19 & 16 & 19 & 38 & nd \\
\hline
\end{tabular}




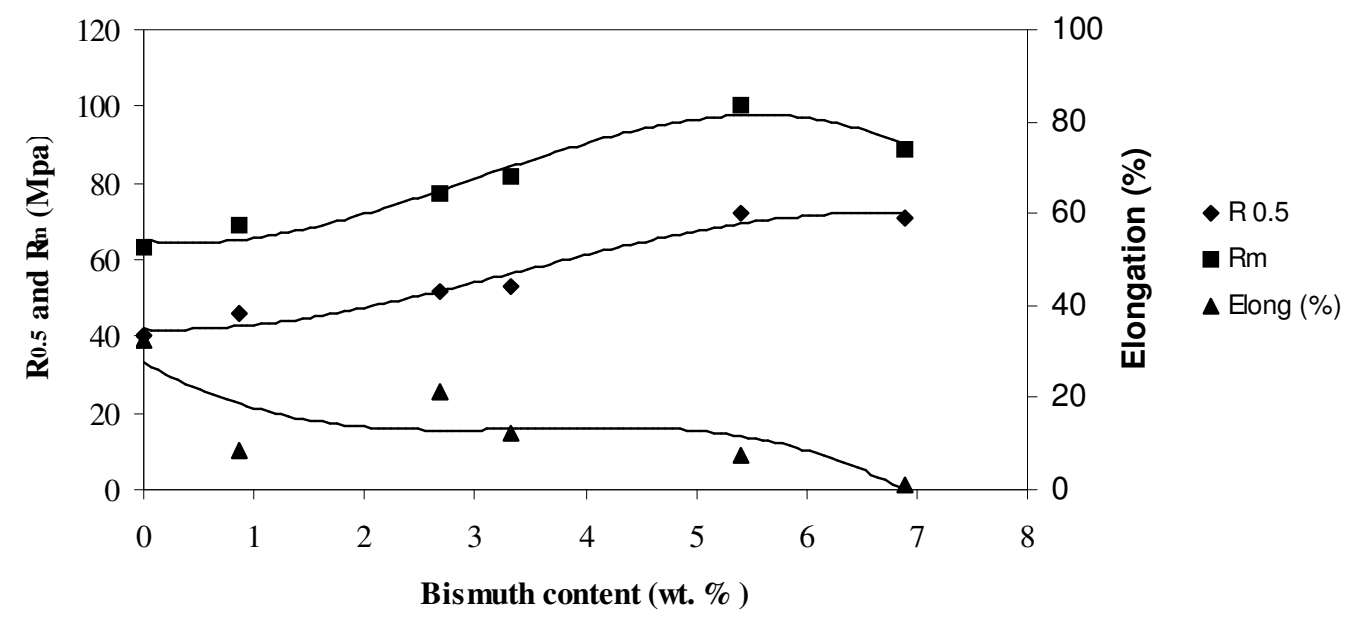

Figure 1 - Influence of Bi contents on the yield strength, ultimate tensile strength and elongation at rupture obtained in produced alloys (alloys 1 to 6 ).

The yield and ultimate tensile strength obtained for the Sn-Zn-Al alloy are a little higher than the obtained in the standard alloys (alloys 7 and 8) [9]. The addition of $\mathrm{Bi}$, up to $~ 5.5$ wt.\%, increases the yield and ultimate tensile strength of the alloys. Despite the dispersion of the values, the ductility values show that the presence of $\mathrm{Bi}$ reduces the elongation at fracture of the alloys. Lowering $\mathrm{Zn}$ content has the opposite effect, as shown by the increase of ductility in alloy 3 when compared with alloy 4 . The addition of $\mathrm{Bi}$ also changes the fracture behavior of the alloys, from ductile to brittle, as presented in fig. 2 a) and b). The alloys with Bi content higher than $\sim 5 \%$ have brittle fracture.

The homogenization heat treatment reduces the hardness of the alloys, when compared with samples in the as-cast condition. The hardness of the tested alloys is, in all the samples, higher then in the standards alloys (alloys 7 and 8).

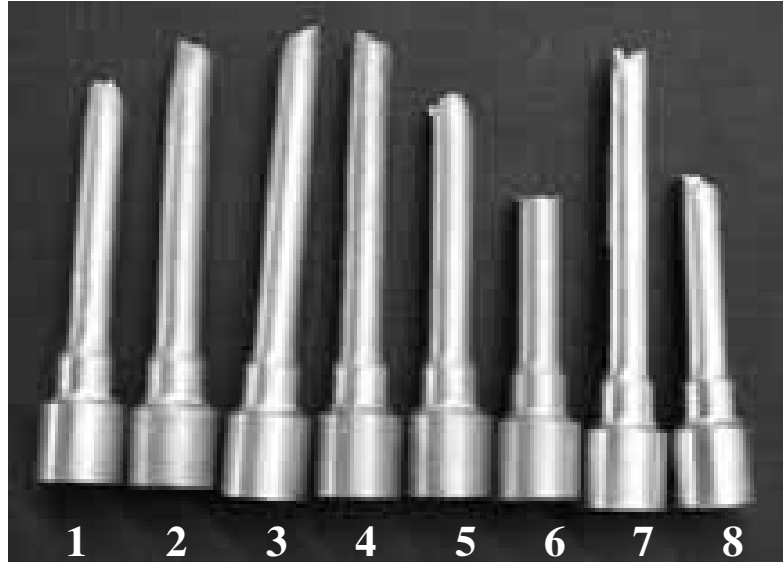

a)

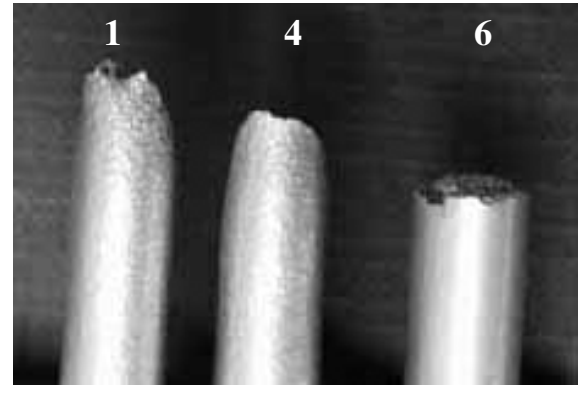

b)

Figure 2 - Fracture morphology of the different alloys a) and detail of the ductile and brittle fracture b) for, respectively, alloys 1,4 and 6 .

Note: Results not determined (nd) in table 2 correspond to the samples with fracture out of the tested zone $\left(1_{0}\right.$ according to EN 10002-1). 
The microstructure of the alloy 1 , of the system $\mathrm{Sn}-\mathrm{Zn}-\mathrm{Al}$, reveals the presence of 3 constituents: matrix, as presented in fig. 4, a zinc rich phase, needles in fig. 3a) and an aluminum rich phase, "stars" in fig. 3a). These results are in accordance with the microstructures obtained by KwangLung et al. [7]. For the smaller additions, bismuth forms a solid solution with the tin rich phase (zone $\mathrm{Z2}$ in fig. 4a) and in table 3). For higher additions of $\mathrm{Bi}$, a separate phase, consisting essentially of $\mathrm{Bi}$ (white phase in fig. 3c), zone $\mathrm{Z4}$ in fig $4 \mathrm{~b}$ ) and table 3, is formed. The solubility of $\mathrm{Bi}$ in the tin rich phase is higher, around $3.7 \mathrm{wt} \%$ in alloy 6 , than the corresponding value for the binary Sn-Bi system (approximately $1 \mathrm{wt} \%$ at room temperature) [8]. The microstructures obtained in the different alloys with various Bi contents are presented in fig. 3.

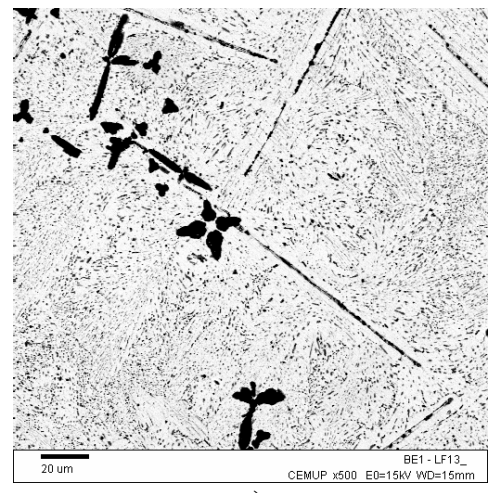

a)

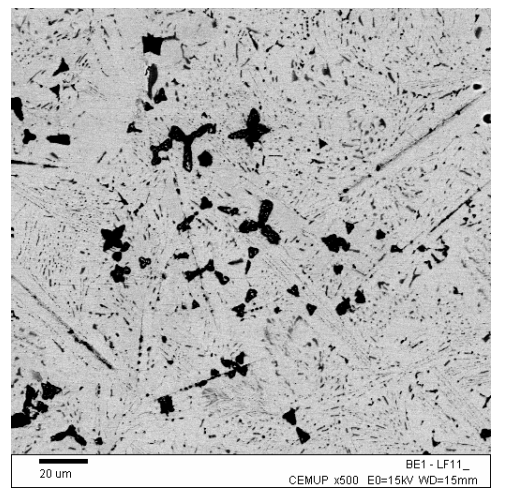

b)

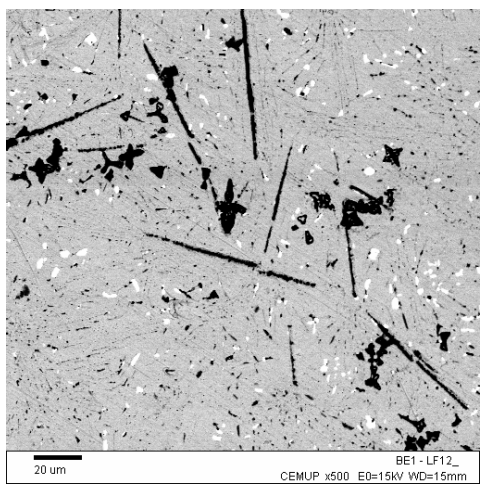

c)

Figure 3 - Microstructures obtained in the alloys, with different Bi contents: a) with $0 \% \mathrm{Bi}$; b) with $0.9 \mathrm{wt} \% \mathrm{Bi}$; c) with $6.9 \mathrm{wt} \% \mathrm{Bi}$ (magnification of 500X).

The chemical composition of the phases and constituents obtained in the different alloys is presented in table 3. In table 3, results for zone $\mathrm{Z} 2$ correspond to mean value of the matrix, constituted by the phases: tin rich phase, an $\mathrm{Al}$ rich phase and a $\mathrm{Zn}$ rich phase (phases 1 to 3 in fig.4a). The morphology of the matrix and the secondary phases are shown in fig. 4, for alloys without $\mathrm{Bi}$ and $6.9 \mathrm{wt} \% \mathrm{Bi}$. All the alloys are constituted by the same phase type and morphology. For $\mathrm{Bi}$ additions higher than $\sim 5 \mathrm{wt} \%$, the Bi rich phase is present (zone Z4 in fig. $4 \mathrm{~b}$ ).

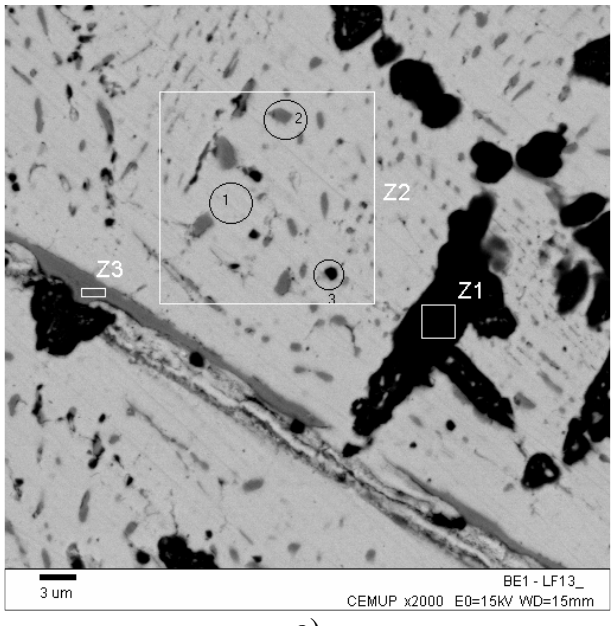

a)

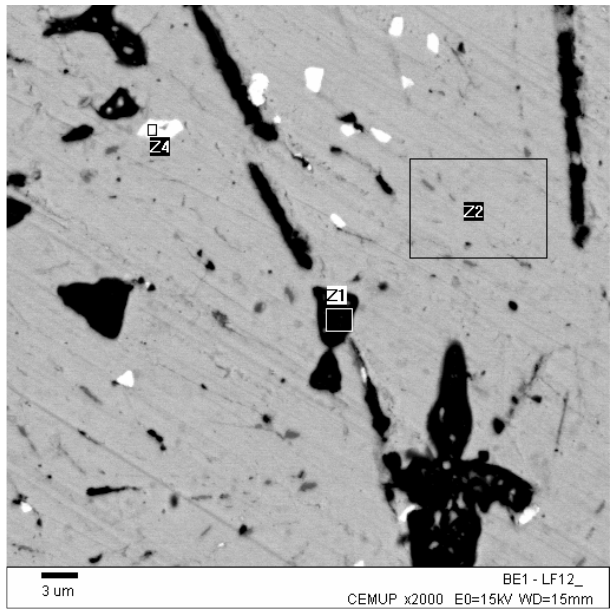

b)

Figure 4 - Detail of the phases and constituents obtained in alloys $1(0 \% \mathrm{Bi})$ a) and $6(6.9 \% \mathrm{Bi}) \mathrm{b})$, and the zones with chemical analysis presented in table 3 (magnification of 2000X). 
Table 3 - Chemical composition of the phases and constituents, obtained by SEM/EDS, present in the alloys 1 and 6 with, respectively, 0 and $6.9 \mathrm{wt} \%$.

\begin{tabular}{cccccc}
\hline Alloy N $^{\text {o }}$ & Zone & $\% \mathrm{Zn}$ & $\% \mathrm{Al}$ & $\% \mathrm{Bi}$ & $\% \mathrm{Sn}$ \\
\hline \multirow{2}{*}{1} & $\mathrm{Z} 1$ & 26.6 & 71.9 & - & rest \\
& $\mathrm{Z} 2$ & 4.4 & 0.2 & - & rest \\
& $\mathrm{Z} 3$ & 98.5 & 0.5 & - & rest \\
\hline \multirow{2}{*}{6} & $\mathrm{Z} 1$ & 31.4 & 64.1 & 0.5 & rest \\
& $\mathrm{Z} 2$ & 3.9 & 0.2 & 3.7 & rest \\
& $\mathrm{Z} 3$ & 98.5 & 0.6 & - & rest \\
& $\mathrm{Z} 4$ & 1.6 & - & 96.5 & rest \\
\hline
\end{tabular}

The decreasing of the mechanical resistance and hardness in alloys 5 and 6 , as shown in fig. 1, can be explained by the formation of the $\mathrm{Bi}$ rich phase (zone $\mathrm{Z4}$ in table 3). The addition of $\mathrm{Bi}$, until approximately $5 \%$, increases the mechanical resistance of the alloys by dissolution of this element in the $\mathrm{Sn}$ rich phase. The maximum Bi solubility in the tin rich phase, for the quaternary alloys, is increased when compared with the binary Sn-Bi system [8]. The others phases or constituents are not significantly affected by the addition of bismuth.

\section{Conclusions}

The tested alloys, from the Sn-Zn-Al and Sn-Zn-Al-Bi systems, have an improved mechanical resistance and ductility when compared with a traditional $\mathrm{Sn}-\mathrm{Pb}$ alloy and lead-free alternative alloy. The addition of Bi increases the mechanical resistance of the Sn-Zn-Al-Bi lead-free alloys. Materials with higher $\mathrm{Bi}$ content have one phase, of high $\mathrm{Bi}$ content, that presents a detrimental effect on the mechanical resistance. The introduction of $\mathrm{Bi}$ is also responsible for the change in the fracture behavior of the alloy, from ductile to brittle.

\section{References}

[1] - K. Suganuma, Current Opinion in solid State \& Materials Science, 5, 55 - 64 (2001).

[2] - S. W. Yoon, J.-R. Soh, B.-J. Lee and H. M. Lee, Acta Mater. 45, 951 (1997).

[3] - K.-L. Lin and L.-H. Wen, Journal of Materials Science in Electronics, 9, 5 - 8 (1998).

[4] - A. Sebaoun, D. Vincent and D. Tréheax, Materials Science and Technology, 3, 241-248 (1987).

[5] - M. Abtew and G. Selvaduray, Materials Science and Engineering, 27, 95 - 141 (2000).

[6] - D. Soares, C. Vilarinho, J. Barbosa, R. Silva and F. Castro, IX Conference on Metallurgical Science and Technology, Madrid, 23-25 October, 2003 (accepted for presentation).

[7] - K.-Lung Lin, L.-H. Wen and T.-P. Liu, Journal of Electronic Materials, Vol. 27, No 3, 97-105, (1998).

[8] - Massalski T. B., Binary Alloy Phase Diagrams, American Society for Metals, Metals Park, Ohio (1986).

[9] - T. Siewert, S. Liu, D. R. Smith and J. C. Madeni, Properties of Lead-Free Solders - Release 4.0, National Institute of Standards and Technology \& Colorado School of Mines, February (2002).

\section{Acknowledgements}

The work was financed by the Ecosolda Project under the Program POCTI of Fundação para a Ciência e Tecnologia (FCT). The authors would like to acknowledge the industrial partners involved on the project, RCS - Sistemas de Controlo Remoto, S.A. and Peixinhos Lda. 